\title{
COMPARATIVE STUDIES ON HEAT TRANSFER AND FLUID FLOW IN CORED BRICK AND PEBBLE BED HEATERS
}

\author{
Gokul. $M^{1}$, Krishnan. A. $S^{2}$ \\ ${ }^{1}$ Assistant Professor, Mechanical Engineering, Velalar College of Engineering and Technology, TamilNadu, India \\ ${ }^{2}$ Associate Professor, Department of Mechanical Engineering, Coimbatore Institute of Technology, Coimbatore- \\ 641014, TamilNadu, India
}

\begin{abstract}
The article reports on comparison of transient heat transfer and fluid flow in two different sensible heat storage devices using Computational Fluid Dynamics. The candidate heat storage devices considered were cored brick and pebble bed and air was taken to be the working fluid. Same geometrical, material, porosity and boundary conditions, have been used for both the cored brick and pebble bed heaters, to compare the axial temperature history and pressure drop. The heat storage system comprises alumina, either in form of pebbles of diameter $6.5 \mathrm{~mm}$, packed to a length of $0.455 \mathrm{~m}$ in a $43 \mathrm{~mm}$ diameter pipe, or cored brick of $43 \mathrm{~mm}$ diameter and same length with through holes to have the same porosity (0.48) as that of the former. The conditions at inlet, outlet and lateral surface too have been taken to be same for both the systems. The fluid flow was considered to be incompressible with k-epsilon model to predict turbulence, and the thermo-physical properties of fluid and solid were assumed to remain constant. Simulations carried out for an inlet temperature of $465 \mathrm{~K}$ for velocities ranging from $2 \mathrm{~m} / \mathrm{s}$ to $5 \mathrm{~m} / \mathrm{s}$ revealed that pressure drop in pebble bed to be considerably higher than those in cored brick, while the temperature history exhibited mixed trends.
\end{abstract}

Keywords: Cored Brick, Pebble Bed and Porosity

\section{NOMENCLATURE}

$\mathrm{k}$ Thermal conductivity $(\mathrm{W} / \mathrm{mK})$ or Turbulent kinetic energy as per context $\left(\mathrm{m}^{2} / \mathrm{s}^{2}\right)$

$\mathrm{c}_{\mathrm{p}} \quad$ Specific heat capacity $(\mathrm{J} / \mathrm{kgK})$

$\mathrm{C}_{\varepsilon 1} \& \mathrm{C}_{\varepsilon 2} \quad$ Constants for Turbulence model (1.44 and

1.92 respectively)

$\mathrm{P}_{\mathrm{k}} \quad$ Shear production of turbulence $\left(\mathrm{kg} / \mathrm{ms}^{3}\right)$

$\mathrm{T}$ Temperature (K)

$\mathrm{u} \quad$ Fluid velocity $(\mathrm{m} / \mathrm{s})$

$\mathrm{t} \quad$ Time (s)

Greek symbols

$\varepsilon \quad$ Rate of dissipation of kinetic energy $\left(\mathrm{m}^{2} / \mathrm{s}^{3}\right)$

$\mu \quad$ Dynamic viscosity ( $\mathrm{kg} / \mathrm{m}-\mathrm{s})$

$\rho \quad$ Density $\left(\mathrm{kg} / \mathrm{m}^{3}\right)$

$\sigma \quad$ Prandtl numbers in $\mathrm{k}-\varepsilon$ equation (1 and 1.3)

\section{Subscripts}

f fluid

$\mathrm{k} \quad$ kinetic energy

s solid

$\varepsilon \quad$ Dissipation rate

T Turbulent

\section{INTRODUCTION}

Ever-growing demand for power generation, especially sourced from environment friendly resources has propelled research in the area of energy and environment. Many of the renewable sources of energy are of intermittent in nature, solar and wind energy for instance, of course differing in their period of intermittence. Energy demand and supply however need not match in time, consequently necessitating for its storage. Energy can be stored in multiple ways, such as mechanical, electrical, thermal, to name a few. Devices for storing energy in thermal form can primarily be classified as (a) Sensible Heat Storage (SHS), Latent Heat Storage (LHS) and (c) Thermo-chemical Storage. SHS can be achieved using solid or liquid media and involves storing energy in a material without phase change in the temperature range of the storage process. LHS systems with solid-liquid transition are considered an alternative to SHS systems, although there are presently no commercial applications. SHS systems, such as molten salts, are being used in low temperature applications at commercial scale and are proven technology. There are some advantages for SHS compared to LHS at high temperatures which includes simplicity of design and construction, ease of control and accordingly lower cost.

Many research works have been carried out on pebble bed and cored brick heaters in the past and the technology for their utilization is also reasonably well developed. Khare (2013) [1] suggested that high temperature concretes such as high alumina cement-based materials and alumina-silicate geopolymers, to have good potential as SHS media quoting their inexpensiveness. Menghare (2013) [2] investigated the SHS techniques for solar thermal application, selection criterion for storage material and economic impact of SHS system His study was based on experimental investigation of thermal performance of solar water heating system integrated with SHS system. Likhendra Prasad et al. (2013) 
[3] compared the transient thermal behavior of heat and fluid flow through cored brick heater, made of concrete and cast steel. The authors concluded cast steel to be more effective than the concrete owing to its higher thermal conductivity. Meseret Tesfay (2014) [4] conducted numerical studies on thermal behavior of high-temperature concrete and solid $\mathrm{NaCl}$ (Common salt) SHS. His study concluded that the Solid $\mathrm{NaCl}$ not only required a considerably smaller storage volume of $150.7 \mathrm{~m}^{3}$ than concrete which was $231.2 \mathrm{~m}^{3}$, but also higher efficiency of charging and discharging. Jian Yang et al (2010) [5] carried out numerical analysis on flow and heat transfer inside small pores of some novel structured packed beds. The researchers studied packed beds with non-uniform spherical particles for the first time and some new transport phenomena were obtained. Three-dimensional Navier-Stokes equations and $\mathrm{k}-\varepsilon$ turbulence model with scalable wall function were adopted for computations. Laguerre et al. (2008) [6] presented two approaches for modeling of transient heat transfer by free convection in a packed bed of spheres. The authors also presented comparison of results of modeling with those of experiments. The first approach used direct computational fluid dynamics software which directly solves the Navier-Stokes equations and the local energy equations in the fluid and solid phases. The second approach used dispersed particle method, which takes into account air-particle convection, conduction and radiation between particles and one dimensional conduction inside the packed bed. Xia et al. (2010) [7] reported studies on fluid flow and heat transfer in packed bed for a LHS, where in the researchers introduced many hypotheses were into the previous packed bed models, which consequently influenced the accuracy and authenticity of the numerical calculation. Anica Trp (2005) [8] investigated the thermal behavior of LHS of the shell-and-tube type during charging and discharging cycle has numerically predicted for various heat transfer fluid working conditions and various geometric parameters and it showed good agreement with experimental results. Ezhilarasu and Krishnan (2013) [9] conducted experimental and computational studies on pebble bed heater operating in the range of inlet velocities various from 2 to $6 \mathrm{~m} / \mathrm{s}$ and inlet temperature of $465 \mathrm{~K}$, then results had good agreement with numerical results. The authors used alumina as storage material and air as the working fluid. It was proposed to continue study based on this, and also extend the same for the cored brick heater. In the present work, the hydrodynamic and thermal behaviors of two heat storage heaters are investigated numerically for various inlet velocities and compared the results of two heat storage system based on charging time. These results of simulation would be helpful for further understanding the fluid flow and heat transfer characteristics in two storage heaters and they would also be useful for the optimum design of storage heaters on different size.

\section{MODELING OF TWO SENSIBLE STORAGE}

\section{HEATERS}

In this present study, three dimensional geometries of two sensible storage heaters have been created by using
GAMBIT software, the pre-processor used to construct the flow geometry, along with the mesh generation for solving the equations of motion and continuity. The storage model has been solved by using commercial CFD software package FLUENT, to solve the equations by numerical method for the geometries constructed using Gambit.

\subsection{Pebble Bed Heater}

A solid cylinder of $0.043 \mathrm{~m}$ diameter and length $0.455 \mathrm{~m}$ was created and then 2390 spheres of $6.5 \mathrm{~mm}$ diameter were drawn inside the cylinder by number of layers. A layer arrangement with some angle rotation around the axis within each layer was chosen as shown in Figure 1.The porosity taken here as 0.48. A gap was provided between the two adjacent spheres in the computational modeling in order to avoid the poor quality mesh at the contact points of spheres [9].
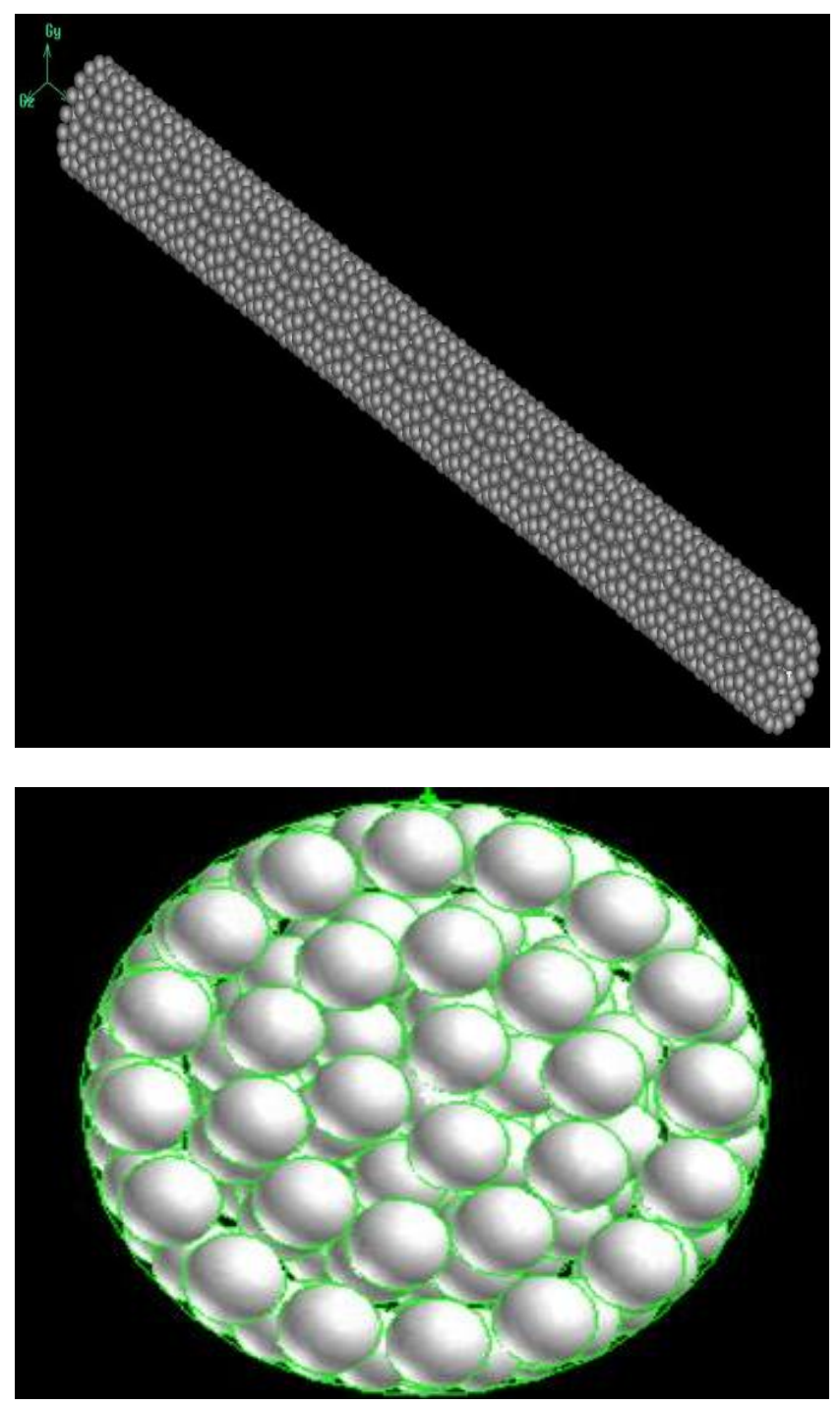

Fig -1: Physical model of pebble bed heater

The discretized geometry is shown in Figure 2. In this tet/hybrid T-grid with size (5-10) based on wall y-plus value greater than 11.5 was adopted. The grid then was exported as a mesh file for simulation. 


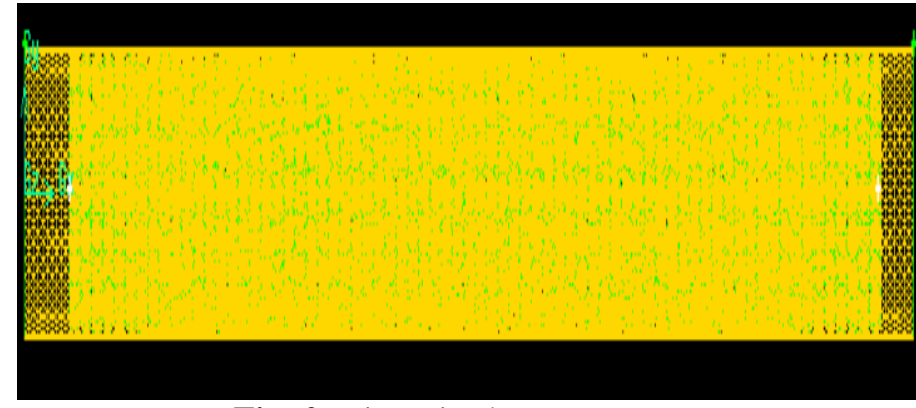

Fig -2: Discretized geometry

\subsection{Cored Brick Heater}

A solid cylinder of diameter $0.043 \mathrm{~m}$ and length $0.455 \mathrm{~m}$ with through holes, 35 in number of $5 \mathrm{~mm}$ diameter was created to obtain the same porosity 0.48 as former as shown in Figure 3. Symmetry was made use of by considering the upper half symmetric portion as the physical model and consequently solved.

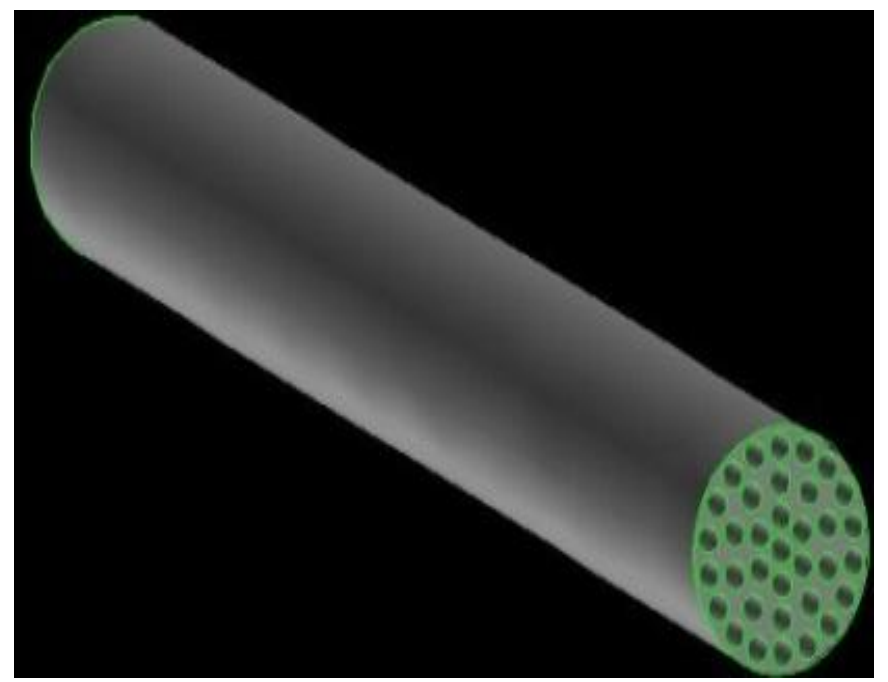

Fig -3: Physical model of cored brick heater

\section{GRID INDEPENDENCE TEST}

The geometry was meshed with unstructured tet/hybrid Tgrid of coarse mesh size 3 was taken in order to have (182087 cells) for whole geometry. Similarly, fine mesh size 1.5 was taken in order to have (658364 cells), it requires more number of iterations per time step for the solution to converge. The simulation was carried out with different gird sizes for inlet velocity $2.212 \mathrm{~m} / \mathrm{s}$ and inlet temperature $465 \mathrm{~K}$, the computational result for different grid size as shown in Table 1. The pressure drop and maximum average cored brick heater temperatures were almost the same for both the mesh sizes, and hence coarse mesh was preferred for simulation.

Table-1: Computational result for different grid size

\begin{tabular}{|l|l|l|}
\hline \multirow{2}{*}{ Parameter } & \multicolumn{2}{|l|}{ Grid(Total Cells) } \\
\cline { 2 - 3 } & 658354 & 182087 \\
\hline Pressure Drop (Pa) & 237.17 & 235.42 \\
\hline $\begin{array}{l}\text { Maximum Average Cored } \\
\text { Brick Temperature (K) }\end{array}$ & 464.87 & 464.53 \\
\hline
\end{tabular}

\section{ASSUMPTIONS}

The following assumptions were made:

- The fluid flow is incompressible

- Radiation heat transfer effects are negligible

- The thermo-physical properties of both the solid and fluid phases are constant during the temperature range investigated

\section{GOVERNING EQUATIONS}

The governing equations for fluid flow and heat transfer through storage heaters as follows:

\section{Fluid Flow}

Continuity:

$$
\nabla \cdot \overrightarrow{\boldsymbol{u}}=0
$$

Momentum:

$$
\rho_{\mathrm{f}} \frac{\mathrm{D} \overrightarrow{\mathrm{u}}}{\mathrm{Dt}}=-\nabla \mathrm{P}+\left(\mu+\mu_{\mathrm{T}}\right) \nabla^{2} \overrightarrow{\mathrm{u}}
$$

Standard k- $\varepsilon$ turbulence model:

Kinetic energy equation

$$
\rho_{\mathrm{f}}(\overrightarrow{\mathrm{u}} . \nabla) \mathrm{k}=\nabla \cdot\left(\left[\mu+\frac{\mu_{\mathrm{T}}}{\sigma_{\mathrm{k}}}\right] \nabla \mathrm{k}\right)+\mathrm{P}_{\mathrm{k}}-\rho_{\mathrm{f}} \varepsilon
$$

Dissipation rate equation

$$
\begin{gathered}
\rho_{\mathrm{f}}(\overrightarrow{\mathrm{u}} . \nabla) \varepsilon=\nabla \cdot\left(\left[\mu+\frac{\mu_{\mathrm{T}}}{\sigma_{\varepsilon}}\right] \nabla \varepsilon\right)+\mathrm{C}_{\varepsilon 1} \mathrm{P}_{\mathrm{k}} \frac{\varepsilon}{\mathrm{k}}-\mathrm{C}_{\varepsilon 2} \rho_{\mathrm{f}} \frac{\varepsilon^{2}}{\mathrm{k}} \\
\mathrm{P}_{\mathrm{k}}=\mu_{\mathrm{T}}\left[\nabla \overrightarrow{\mathrm{u}}:\left(\nabla \overrightarrow{\mathrm{u}}+(\nabla \overrightarrow{\mathrm{u}})^{\mathrm{T}}\right)\right] \\
\mu_{\mathrm{T}}=\rho_{\mathrm{f}} \mathrm{C}_{\mu} \frac{\mathrm{k}^{2}}{\varepsilon}
\end{gathered}
$$

\section{Heat Transfer}

Energy equation:

Convection: Solid - Fluid Interface

$$
\rho_{\mathrm{f}} \mathrm{c}_{\mathrm{pf}} \frac{\mathrm{DT}}{\mathrm{Dt}}=\mathrm{k}_{\mathrm{s}} \nabla^{2} \mathrm{~T}
$$

Conduction: Solid Region

$$
\rho_{\mathrm{s}} \mathrm{c}_{\mathrm{ps}} \frac{\partial \mathrm{T}}{\partial \mathrm{t}}=\mathrm{k}_{\mathrm{s}} \nabla^{2} \mathrm{~T}
$$

Table-2: Material properties

\begin{tabular}{|l|l|l|l|}
\hline \multicolumn{2}{|l|}{ Name } & $\begin{array}{l}\text { Alumi } \\
\text { na }\end{array}$ & Air \\
\hline \multicolumn{2}{|l|}{ Material Type } & Solid & Fluid \\
\hline \multirow{2}{*}{$\begin{array}{l}\text { Property } \\
\text { and value }\end{array}$} & Density $\left(\mathrm{kg} / \mathrm{m}^{3}\right)$ & 3970 & 1.225 \\
\cline { 2 - 4 } & Specific heat $(\mathrm{J} / \mathrm{kg} \mathrm{K})$ & 775 & 1006.43 \\
\hline
\end{tabular}




\begin{tabular}{|l|l|l|l|}
\hline & $\begin{array}{l}\text { Thermal conductivity } \\
(\mathrm{W} / \mathrm{m} \mathrm{K})\end{array}$ & 36 & 0.0242 \\
\cline { 2 - 4 } & $\begin{array}{l}\text { Dynamic viscosity } \\
(\mathrm{kg} / \mathrm{m}-\mathrm{s})\end{array}$ & $-1.79 \times 10^{-5}$ \\
\hline
\end{tabular}

\section{INITIAL AND BOUNDARY CONDITIONS}

Same initial and boundary conditions were imposed for both the storage devices. These are as follows:

- Initially, all the domains were at assumed to be at a constant temperature of $300 \mathrm{~K}$.

- Inlet was specified as velocity inlet, which was set as uniform air velocity with appropriate temperature.

- $\quad$ Outlet was specified as pressure outlet, which fixes static pressure as $1.013 \times 10^{5} \mathrm{~Pa}$.

- $\quad$ Outer surfaces were insulated except inlet and outlet.

\section{SOLUTION TECHNIQUES}

The governing equations were solved by using commercial CFD software package, FLUENT 6.3.26. The following options were exercised in the FLUENT software:

- The set of governing equations was solved in a segregated fashion, which means that the discretized momentum and energy equations were solved one by one during the iterations.

- Unsteady state was formulated as first order implicit condition and cell based gradient option was considered.

- Interfaces of solid and fluid phases were made coupled

- Velocity and pressure coupling were handled with SIMPLE algorithm.

- Discretization schemes:
Pressure: PRESTO, Momentum, Turbulence kinetic energy and dissipation rate and energy: First order upwind.

- Under-relaxation factors:

$\begin{array}{ll}\circ & \text { Pressure }: 0.3 \\ \circ & \text { Density }: 1 \\ \circ & \text { Body forces : } 1 \\ \circ & \text { Momentum }: 0.2-0.4 \\ \circ & \text { Volume fraction }: 0.5 \\ \circ & \text { Granular temperature }: 0.2 \\ \circ & \text { Turbulent kinetic energy }: 0.8 \\ \circ & \text { Turbulent dissipation rate }: 0.8 \\ \circ & \text { Turbulent viscosity }: 1\end{array}$

Simulations were carried out for various inlet velocities ranging from 2 to $5 \mathrm{~m} / \mathrm{s}$ with temperature $465 \mathrm{~K}$ for both heaters to predict pressure drop, velocity distribution and axial temperature distributions.

\section{RESULTS AND DISCUSSION}

\subsection{Pressure Drop across the Storage Heaters}

The pressure drop through the pebble bed depends on superficial velocity, porosity, mean particle diameter of sphere and diameter of holes, dynamic viscosity and density of fluid. A comparison of pressure drop across the heater for the two storage heaters for velocity ranging from $2 \mathrm{~m} / \mathrm{s}$ to 5 $\mathrm{m} / \mathrm{s}$ is shown in Figure 4. It can be seen that the pressure drop in the pebble bed is higher than that of cored brick at least by an order and the difference diverges with increase in velocity. This could be attributed to difference in flow pattern. The flow in pebble bed changes its direction continuously as it passes through the pebbles, which introduces significant additional resistance [9]. However, the flow in cored brick is straight through and fairly simpler, resulting in lesser pressure drop.

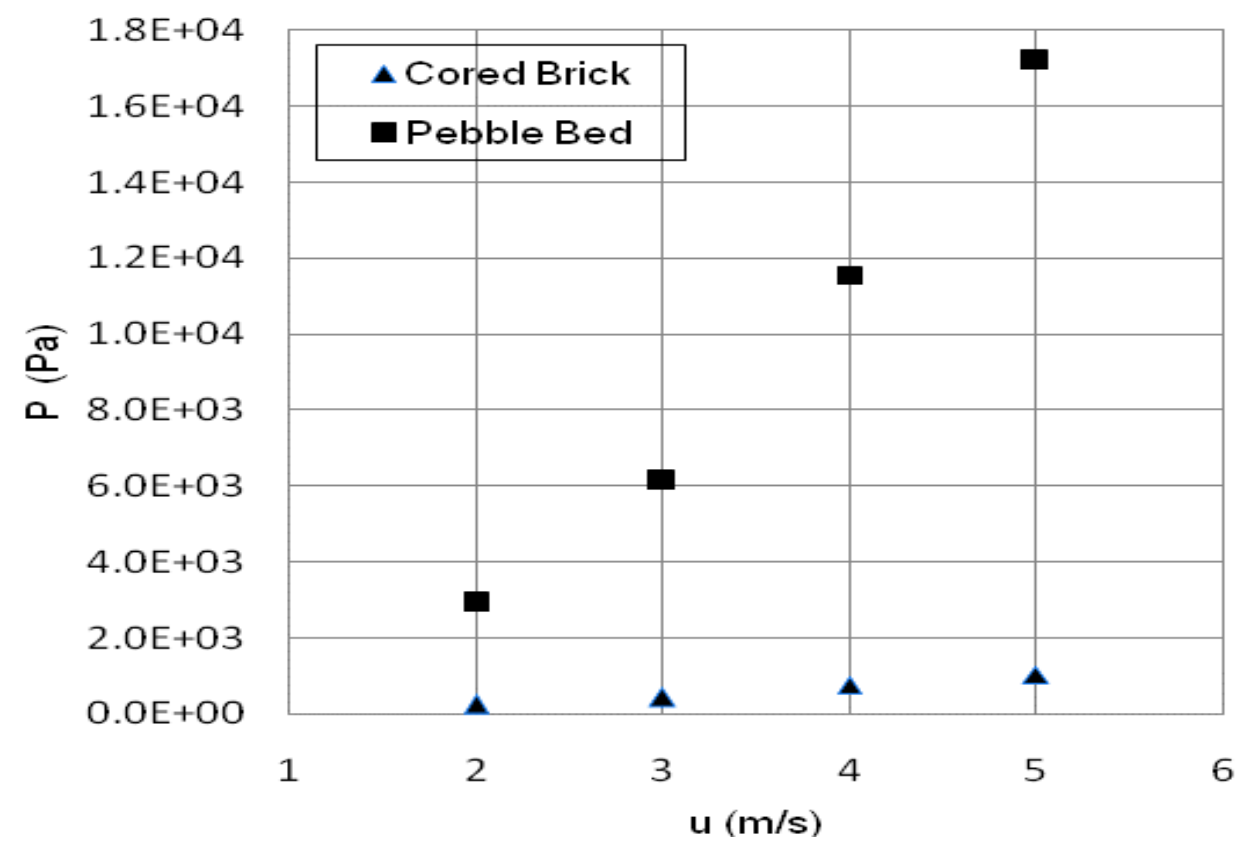

Fig -4: Comparison of pressure drop for two storage heaters 


\subsection{Temperature Distribution}

During the heating process, the storage material received heat from air, which was used as working fluid. The temperature of the bed varies with time and space. The axial variation of temperature was predicted for an inlet velocity and temperature of $2 \mathrm{~m} / \mathrm{s}$ and $465 \mathrm{~K}$ respectively. The results of the same for pebble bed and cored brick heaters are shown in Figures 5 and 6 , in order. In Figure 5, which represents axial temperature variation for pebble bed, it can be noticed that data points of same colors form two different lines. For any one color, the line on top represents the temperature of air and that on the bottom depicts the temperature of the pebble. With the passage of time, the gap between these two diminishes as expected, since the pebbles get heated up. The variation of temperature of the storage material along the length for the cored brick is presented in Figure 6 . It can be inferred from Figures 5 and 6, that the time required for pebble bed to get fully charged is more than $150 \%$ that required for the cored brick.

It could be expected that an increased pressure drop results in an increased heat transfer rate and hence the pebble bed to be quicker than the cored brick to get charged. The simulation result however shows the other way around which could be explained as below:

Buttressing on stringent arguments, all the three modes of heat transfer takes place in the storage heater. Ignoring the effects of contribution from radiation, the convection and conduction signify themselves in the heat transport in each of the heaters. The zigzag flow pattern in the pebble bed and consequently higher turbulence results in higher convective heat transfer than in the cored brick heater. However, the limiting of inter-pebble contacts to points as against a continuum in cored brick severely resists conduction and thus resulting in a net lesser heat transfer.

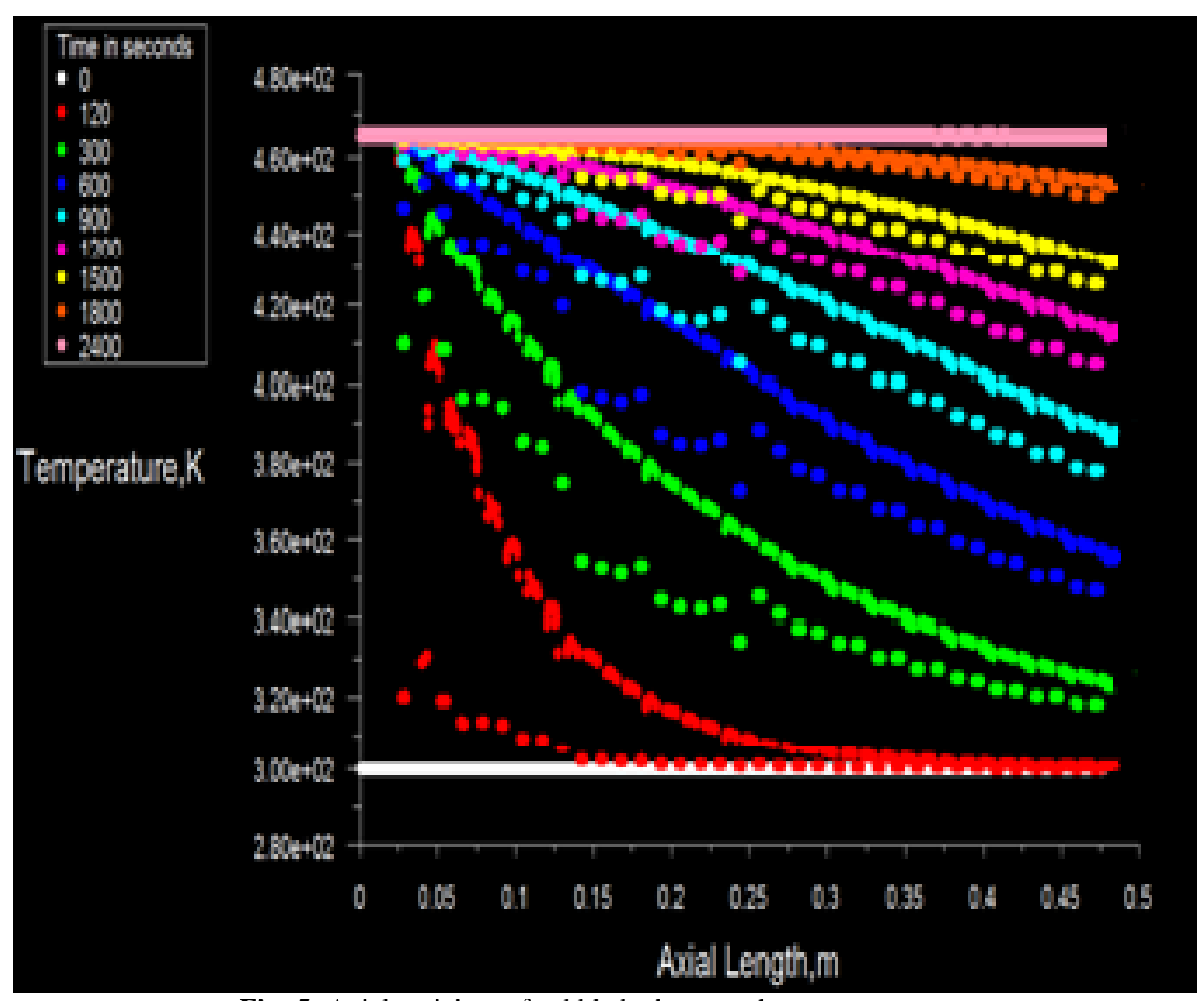

Fig -5: Axial variaiton of pebble bed storage heater temperature 


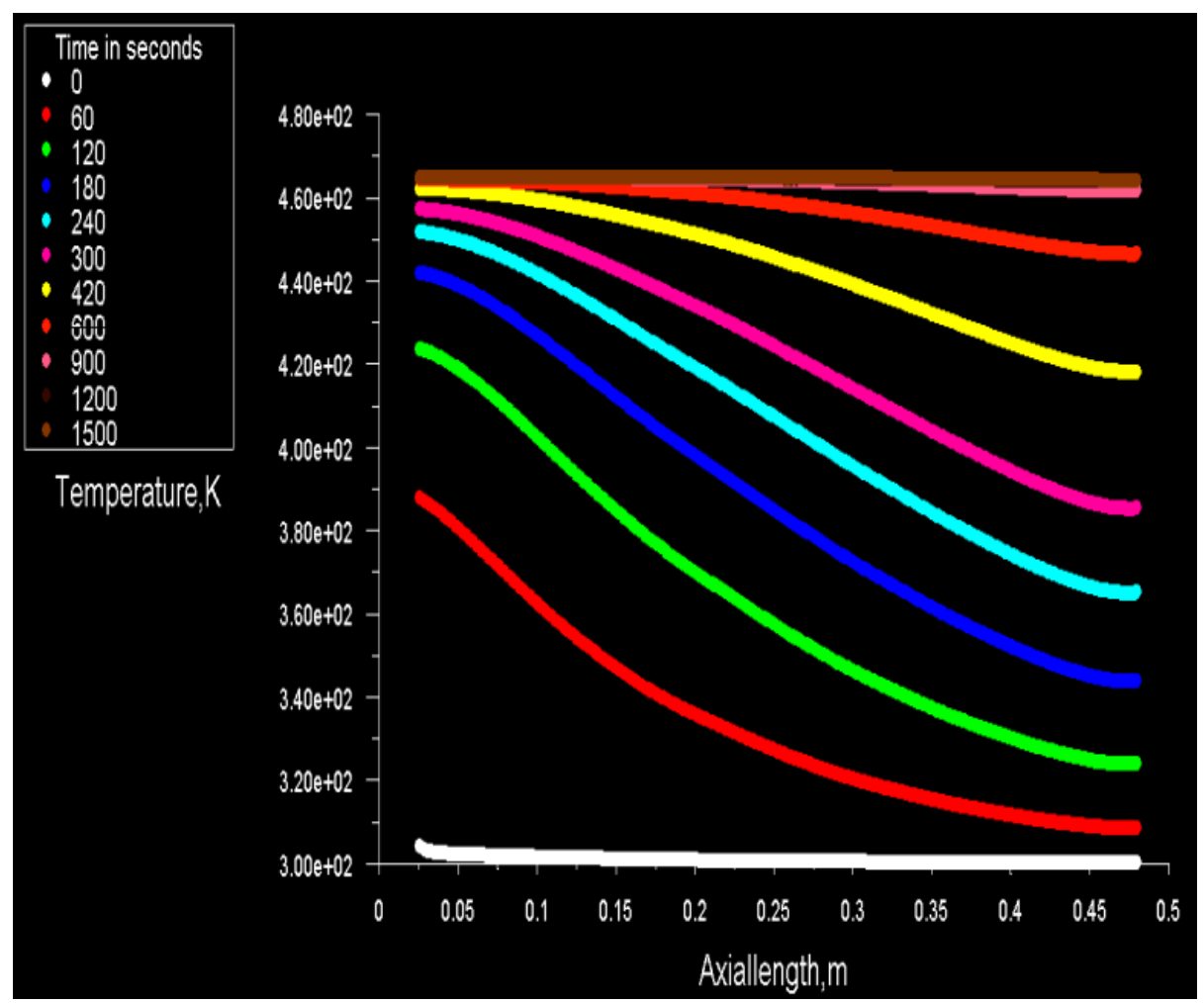

Fig -6: Axial variaiton of cored brick storage heater temperature

The results of variation of axial temperature for the two heaters for inlet velocity ranging from $2 \mathrm{~m} / \mathrm{s}$ to $5 \mathrm{~m} / \mathrm{s}$ are as shown in Figures 7 and 8 . The overall heat transfer rate of storage bed depends strongly on inlet velocity of working fluid. Increasing inlet velocity of fluid increases the overall heat transfer rate, that enable faster exchange of heat. The maximum and minimum temperature of cored brick heater for various velocities is presented in Figures 9 and 10.

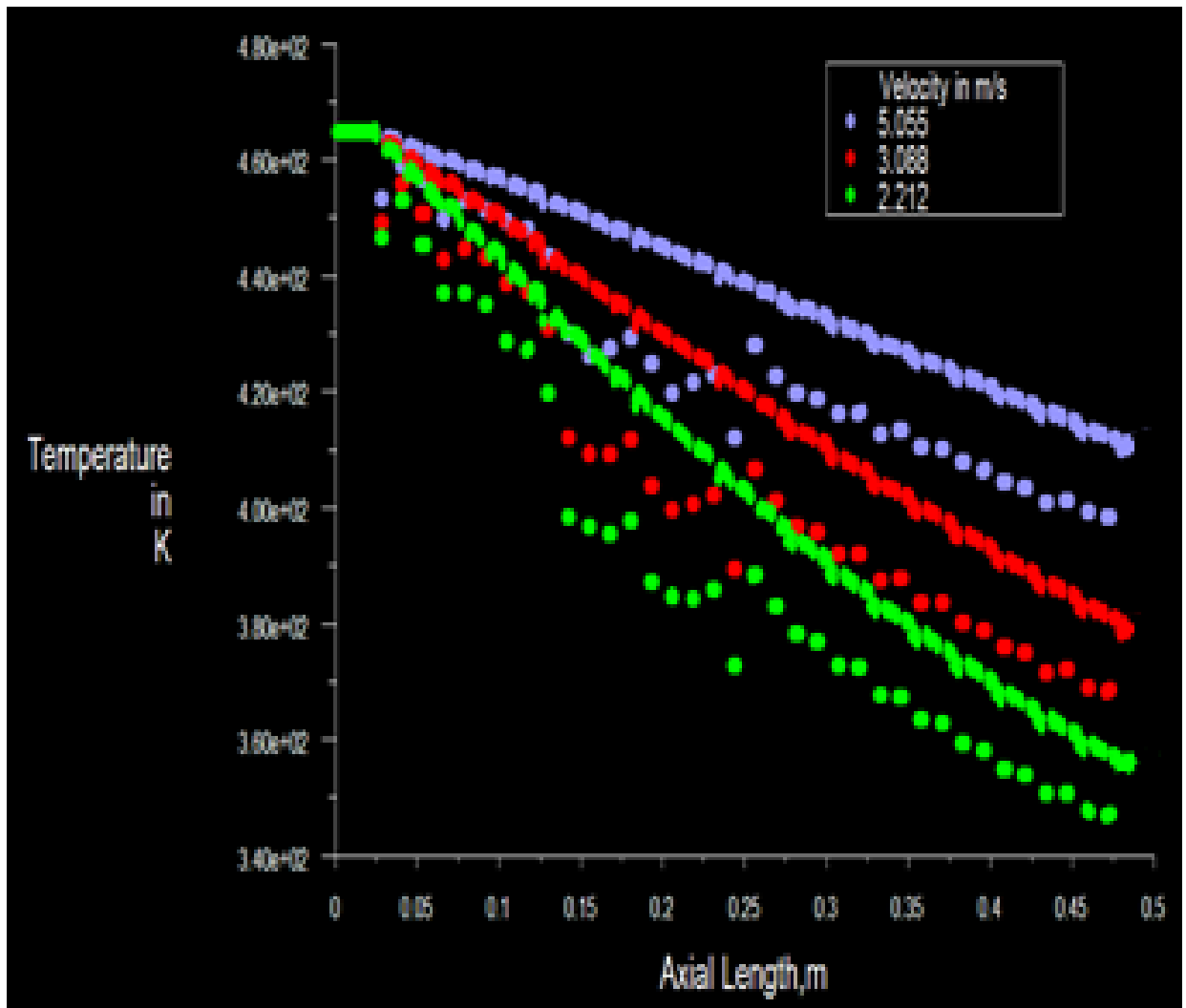

Fig -7: Effect of air velocity on charging time of pebble bed heater at time $(t=300 \mathrm{~s})$ 


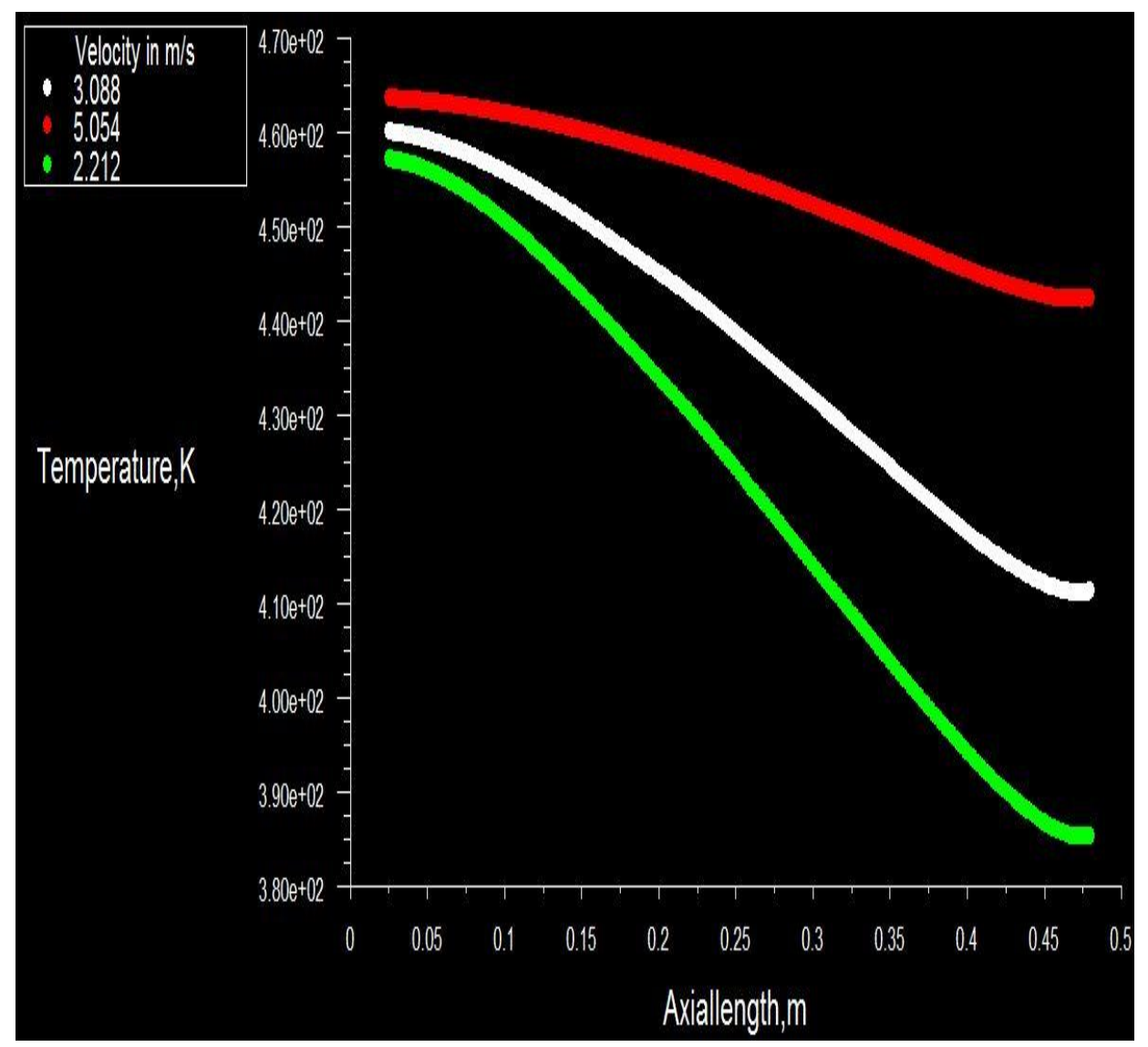

Fig -8: Effect of air velocity on charging time of cored brick heater at time ( $\mathrm{t}=300 \mathrm{~s})$

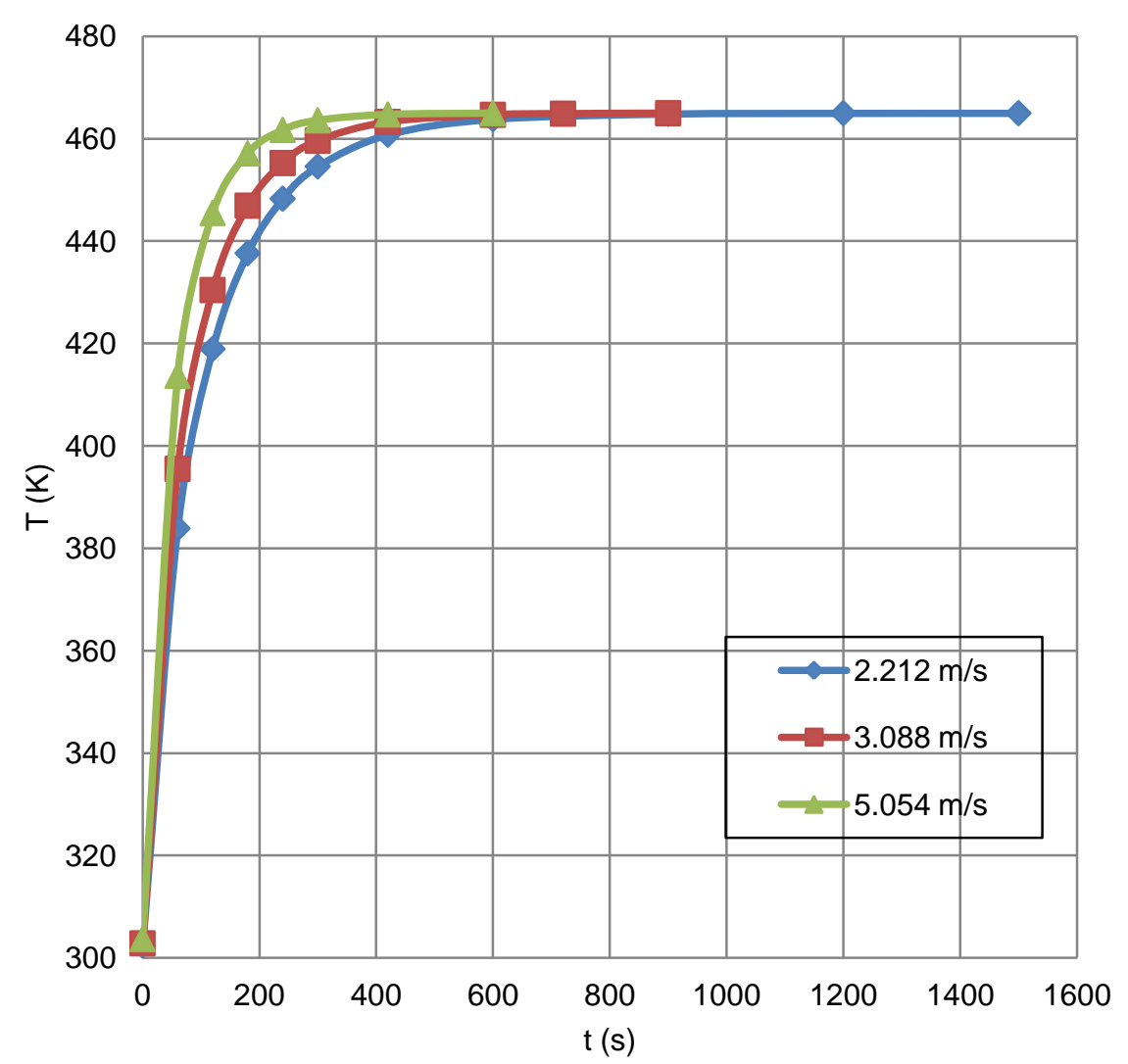

Fig -9: Maximum temperature of cored brick heater for various velocities 


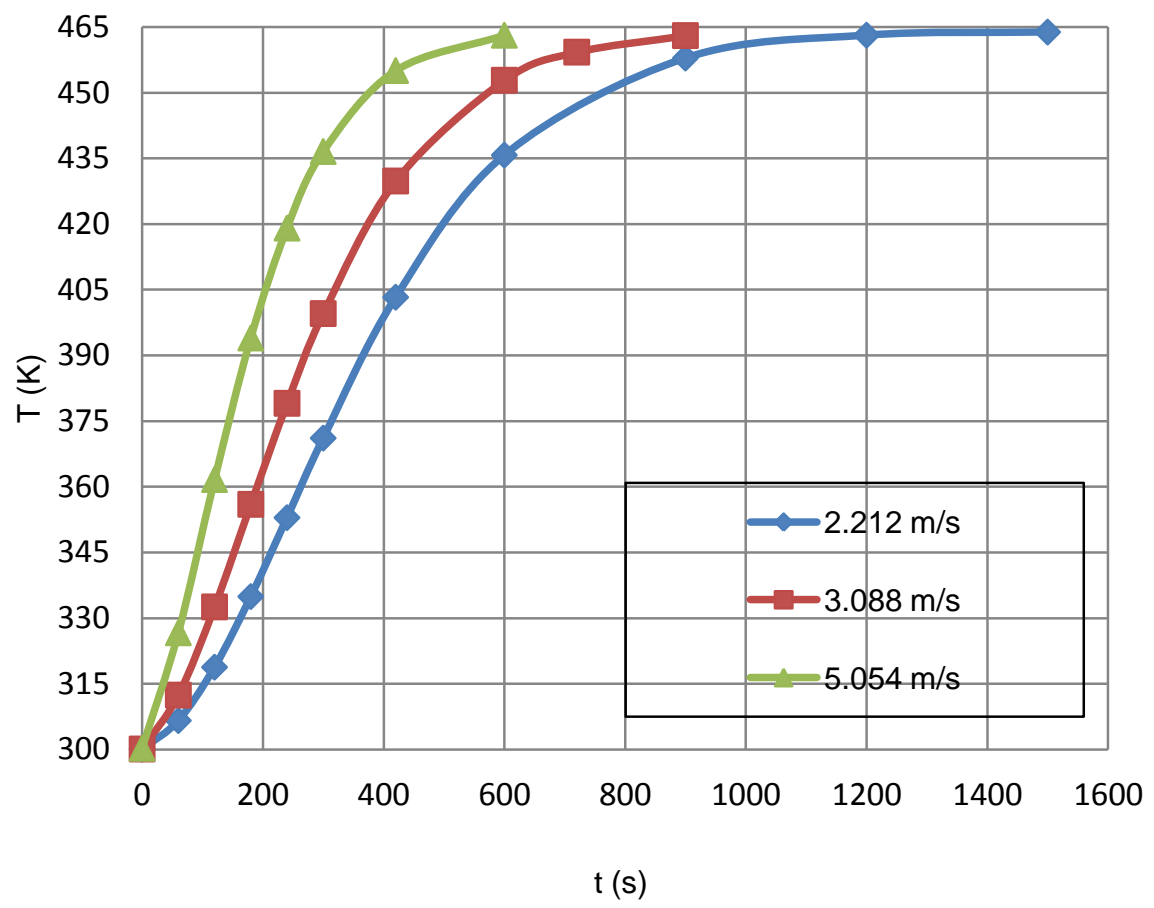

Fig -10: Minimum temperature of cored brick heater for various velocities

\subsection{Charging Time Requirement}

The Figure 11 depicts the charging time of two storage heaters for inlet velocity $2 \mathrm{~m} / \mathrm{s}$ and inlet temperature $465 \mathrm{~K}$. The average temperature of two heaters for various time intervals was computed by using volume integral option.

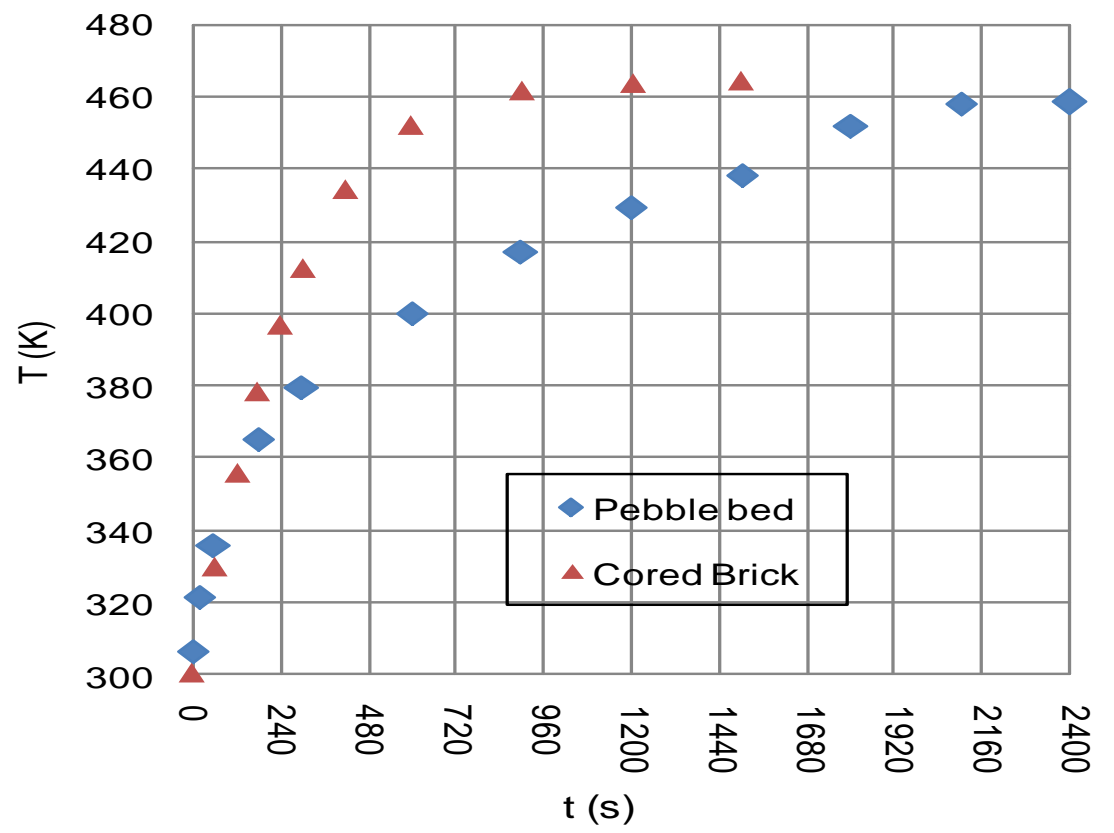

Fig -11: Charging time comparison of two storage heaters for velocity v=2 m/s

Initially, the driving potential of heat transfer was higher for both storage heaters and this driving potential decreases with increasing of time but pebble bed heater had much low heat transfer driving potential than the cored brick heater. During the initial charging period, the pebble bed appears to be heated more than its counterpart. However, with the passage of time, it can be seen that the heating of cored brick accelerates and attains the maximum temperature of $465 \mathrm{~K}, 15$ minutes before than that of pebble bed storage heater. 


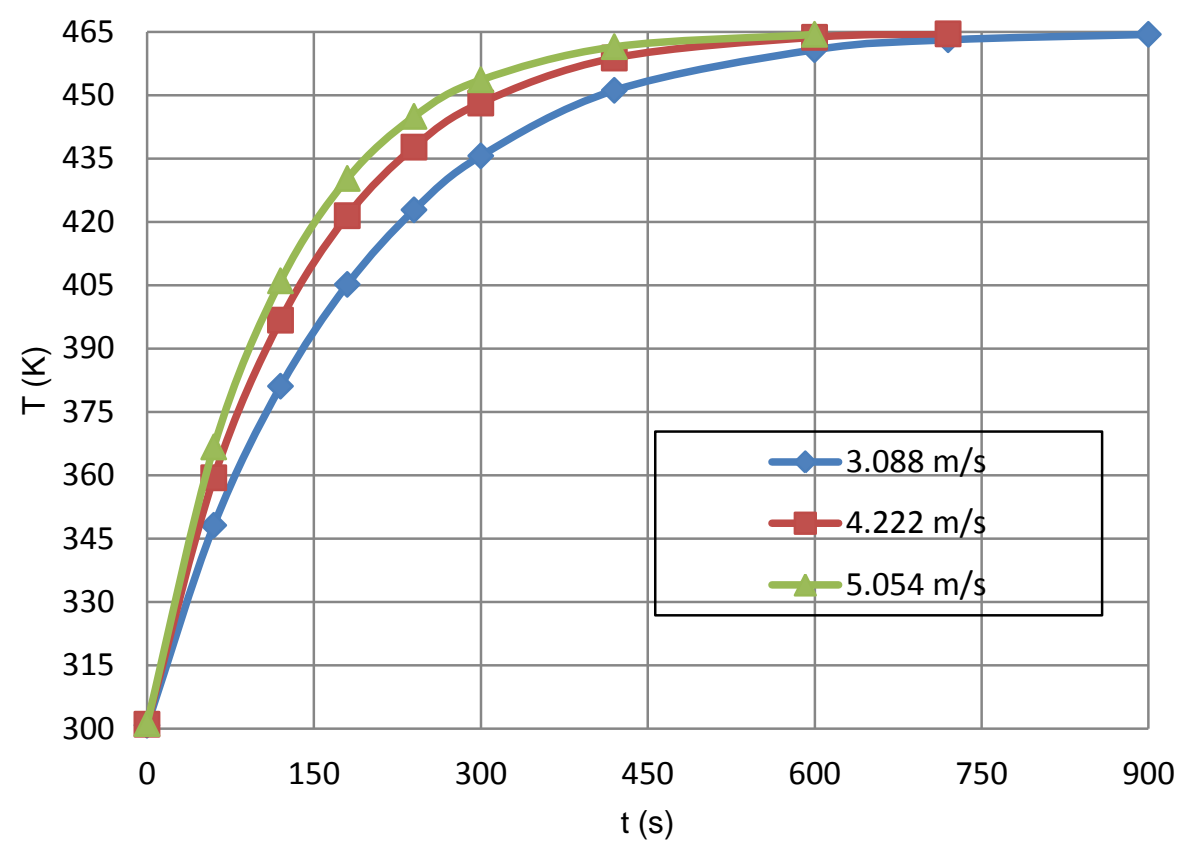

Fig -12: Charging time comparison of cored brick heater for various velocities

As discussed earlier, this could be attributed to dominance of conduction in cored brick being much higher in magnitude compared to the pebble bed, for the latter has only point contact. The charging time for cored brick heater for various velocities is depicted in Figure 12.

\section{CONCLUSION}

The transient thermal and hydrodynamic behaviors of two storage heater had studied in this research article. The pressure drop and temperature history of two storage heaters during charging were discussed for different inlet velocity. It can be concluded that the higher pressure drop occur in pebble bed compared to cored brick storage heater for same porosity while the time taken to attain the maximum temperature of cored brick heater was much less than pebble bed heater during charging process. Hence, the cored brick heater can be considered as a viable alternative to the pebble bed, when alumina is considered as the storage material.

\section{ACKNOWLEDGMENTS}

The authors express their profound gratitude to the Principal and Management of Coimbatore Institute of Technology, Coimbatore, INDIA, for providing the necessary infrastructure and encouragement.

\section{REFERENCES}

[1]. Khare, S., Dell'Amico, M., Knight, C., and McGarry, S., 2013, "Selection of Materials for High Temperature Sensible Energy Storage", Solar Energy Materials \& Solar Cells 115, pp.114-122.

[2]. Menghare, Yogesh M., Jibhakate, Y. M., 2013, "Review on Sensible Heat Storage System Principle, Performance and Analysis", International Journal of Engineering Research \& Technology, Vol.2, Issue 6, pp. 3432-3435.
[3]. Likhendra Prasad, Hakeem Niyas, Muthukumar, P., 2013, "Performance Analysis of High Temperature Sensible Heat Storage System during Charging and Discharging Cycles", $4^{\text {th }}$ International Conference on Advances in Energy Research 278, pp. 1240-1247.

[4]. Meseret Tesfay, 2014, "CFD Analysis of Sensible Thermal Energy Storage System Using Solid Medium in Solar Thermal Power Plant", International Journal of Advances in Engineering \& Technology, Vol.6, Issue 6, pp. 2766-2783.

[5]. Jian Yang, Qiuwang Wang, Min Zeng, Akira Nakayama, 2010, "Computational Study of Forced Convective Heat Transfer in Structured Packed Beds with Spherical or Ellipsoidal Particles", Chemical Engineering Science 65, pp. 726-738.

[6]. Laguerre, O., Ben Amara, S., Alvarez, G., Flick, D., 2008, "Transient Heat Transfer by Free Convection in a Packed Bed of Spheres: Comparison between Two Modelling Approaches and Experimental Results", Applied Thermal Engineering 28, pp.14-24.

[7]. Xia, L., Zhang, P., Wang, R.Z., 2010, "Numerical Heat Transfer Analysis of the Packed Bed Latent Heat Storage System Based on an Effective Packed Bed Model", Energy 35, pp.2022-2032.

[8]. Anica Trp., 2005, “An Experimental and Numerical Investigation of Heat Transfer during Technical Grade Paraffin Melting and Solidification in a Shell-and-Tube Latent Thermal Energy Storage Unit", Solar Energy 79, pp.648-660.

[9]. Ezhilarasu, M., Krishnan, A.S., 2013, "Experimental and Computational Studies on Transient Heat Transfer and Fluid Flow in a Packed Bed", Proceedings of $13^{\text {th }}$ UK Heat Transfer Conference, UKHTC2013/199, pp. 1-8. 


\section{BIOGRAPHIES}

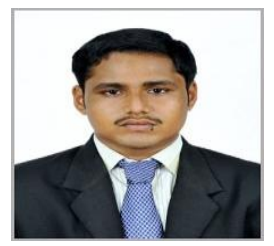

Gokul. M has obtained his M.E. - Heat Power Engineering from Coimbatore Institute of Technology, Coimbatore, India (2014) and his B.E. degree in Mechanical Engineering from Nandha Engineering College, Erode, India in 2012. His areas of interest are Thermal science and Fluid mechanics etc. He is currently working as Assistant Professor in the department of Mechanical Engineering in Velalar College of Engineering and Technology, Erode, India.

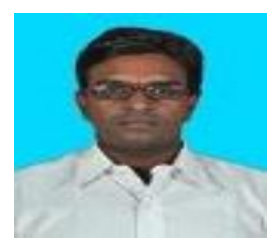

Dr. A. S. Krishnan has obtain his doctoral degree in the field of heat transfer from Indian Institute of Technology, Madras and his postgraduation from Coimbatore Institute of Technology, Coimbatore in 2000. He completed his under graduation in Mechanical Engineering from Mepco Schlenk Engineering College, Sivakasi in 1998. He holds experiences both in Academic as well as Industrial Research. He is currently working as Associate Professor in the department of Mechanical Engineering in Coimbatore Institute of Technology, Coimbatore, India. $\mathrm{He}$ is also supervising scholars towards their doctoral degrees in various topics in Thermal Engineering. 